\title{
CHANGES IN SOME PERFORMANCE INDICATORS FOLLOWING THE IMPLEMENTATION OF AN EXPERIMENTAL MODEL FOR BODY CORPUS MUSCLE STABILITY IN PHYSICAL EDUCATION AND SPORTS CLASSES
}

\author{
S. Belomazheva-Dimitrova* \\ Faculty of Education, St Cyril and St. Methodius University of Veliko Tarnovo, \\ VelikomTarnovo, Bulgaria
}

\begin{abstract}
Muscles of the trunk are responsible for the movement and stability of the spine. Very often children worsen their body posture in school-age because of weak musculature and bad studying position.

THE PURPOSE of the study is to apply an experimental model of body corpus muscle stability in physical education and sports classes and to compare the strength performance indicators of those muscles before and after the experiment.

METHODS: The contingent of the study represents 21 students on average age 12.4 years. Data of anthropometric indicators, static and dynamic strength indicators of body corpus muscles and degree of mobility of the spine were collected during the experiment. All data were processed and statistically analyzed.

RESULTS: The analysis of the results shows that the implementation of the experimental model of exercises significantly improves the static and dynamic muscular strength of body corpus muscles and does not increase the flexibility of the spine.

CONCLUSIONS: We can conclude that the obtained results confirmed the effectiveness of the experimental model of exercises and it could be included in ordinary Physical education and sports classes like the opportunity to counteract of poor body posture and spinal deformities.
\end{abstract}

Key words: body posture, spinal deformities, muscles, prevention, physical education.

\section{INTRODUCTION}

Population health is a complex biological, demographic and social process that reflects the level of economic and cultural development in society, the state of the health infrastructure and the natural conditions (1).

According to Simeonov, D. (2013) health system includes institutions, organizations, authorities and activities to protect, heal, strengthen and recover people's health (1). One of these institutions is school, which provides knowledge about human health through school subjects such as Man and nature, Biology and health education,

\footnotetext{
*Correspondence to: Stefaniya BelomazhevaDimitrova, St Cyril and St. Methodius University of Veliko Tarnovo, Faculty of Education, 5000, VelikomTarnovo, Bulgaria, e-mail: stefanial@abv.bg
}

Chemistry and environmental protection, Physical education, etc.

The term "quality of life" first appeared in 1960. One of its aspects has to do with satisfaction with life activities of the population in time and space, another one is the chance for individual personality development (2). The physical condition of an individual is a function of all those aspects of the quality of life. The lack of pain, disease, discomforts and on the other hand the feeling of health, strength and satisfaction when performing various motor activities increase the quality of life.

Poor working posture, immobilization of modern day children and weak muscles supporting the spine in an upright position, which leads to pain and malformation, are 
problems of capital social importance. The main objective of Physical education as a subject is to ensure proper motor development of pupils. It creates preconditions for good health and personal fulfillment through increasing motor abilities and strengthening the body, thus improving the quality of life and investing in health for the more advanced stages of an individual's life.

This article should direct the attention of specialists to the potential of Physical education as a subject to improve performance and body muscle strength through targeted exercise.

Reiman and Manske (2009) believe that all people should have basic level of ability to perform functional movements, needed for the successful performance of their everyday and professional activities (3).

Improving the quality of the basic functional models of movement, building the basis of motor abilities leads to a reduction of injuries, improvement of motor efficiency and quality of life (4). Functional movements require an optimal level of development of the components of mobility and stability: range of movement in joints, muscle flexibility, muscle strength and endurance, coordination, balance, and postural control (5). The ability to produce and maintain a balance between mobility and stability along the kinetic chain while performing fundamental movement patterns with accuracy and efficiency is the definition of functional movements (6).

Some authors define the ability to perform functional movement skills tests and state that their good level is a precondition for a good performance of the basic motor skills such as running, jumping, throwing, etc. (7).

According to Akuthoha (2008) there are broad benefits from core stabilization, from improving athletic performance and preventing injuries, to relieving lower back pain.

The muscle core can be described as a muscular box with the abdominal muscles in the front, paraspinal and gluteal muscles in the back, the diaphragm as the roof, and the pelvic as a floor and hip girdle musculature as the bottom (8). According to a number of scientific publications core stability exercises leading to the prevention of different musculoskeletal conditions and spinal disorders. (9)
The first stage in developing muscle core stability is to strengthening the abdominal muscles (10). Hodges and Richardson showed that it is not simply that deep-layer abdominal muscles need to be strengthened and the spine to be stabilized, but it is important how they are recruited (11).

Some Bulgarian authors study the stability of the spine and conduct researches with different functional tests in students, but this type of studies in recent years has not been conducted with pupils (12-14).

Research hypothesis: we believe that the application of an experimental training model including functional movement and exercises as part of Physical education and sports classes will lead to strengthening body corpus muscles and creating a balance between strength and flexibility.

The objective of the current study is to apply an experimental model for body stability in Physical education and sports classes and to establish how effective it is.

\section{METHODS}

Research participants are 21 pupils from the town of Ruse, 11-12 years old, among which 12 girls and 9 boys. None of them has experience in practicing specialized exercises for strengthening body corpus muscles before the beginning of this experiment, and the sets of exercises used in the study are novel to all pupils.

The following research methods have been applied in the experiment:

1. Study of anthropometric indicators: height, weight and Body mass index. The body mass index for children and teenagers differs from the index for adults. Assessment criteria can be seen in Table 1 (15).

2. Specialized tests for spine mobility (depth of bend, depth of bend to the left and right) and tests for static and dynamic strength endurance of abdominal and back muscles (number of body lifts from a upine position and lying position for as long as possible and lifting the body up to 45 degrees from supine position and lying position and holding, recording the number of seconds) (16).

Experimental training model - includes functional movements and exercises that aim at strengthening the abdominal and back muscles, as well as such that establish healthy posture 
habits. They are divided into two 5-minute sets in the preliminary and main lesson parts. Three different varieties of exercises have been
BELOMAZHEVA-DIMITROVA S. developed, so that they can be alternated throughout the academic week, thus providing opportunities for diversity.

Table 1. Criteria for assessing normal weight in children

\begin{tabular}{|c|c|c|c|c|c|c|}
\hline \multirow{2}{*}{ Age } & \multicolumn{3}{|c|}{ Boys } & \multicolumn{3}{c|}{ Girls } \\
\cline { 2 - 7 } & $\begin{array}{c}\text { Criteria for } \\
\text { underweight }\end{array}$ & $\begin{array}{c}\text { Criteria for } \\
\text { overweight }\end{array}$ & $\begin{array}{c}\text { Criteria for } \\
\text { obesity }\end{array}$ & $\begin{array}{c}\text { Criteria for } \\
\text { underweight }\end{array}$ & $\begin{array}{c}\text { Criteria for } \\
\text { overweight }\end{array}$ & $\begin{array}{c}\text { Criteria for } \\
\text { obesity }\end{array}$ \\
\hline 9 & 14.03 & 19.10 & 22.77 & 13.87 & 19.07 & 22.81 \\
\hline 10 & 14.40 & 19.84 & 24.00 & 14.20 & 19.86 & 24.11 \\
\hline 11 & 14.80 & 20.55 & 25.10 & 14.60 & 20.74 & 25.42 \\
\hline 12 & 15.20 & 21.22 & 26.02 & 14.90 & 21.68 & 26.67 \\
\hline 13 & 15.70 & 21.92 & 26.84 & 15.40 & 22.58 & 27.76 \\
\hline 14 & 16.20 & 22.62 & 27.63 & 15.70 & 23.34 & 28.57 \\
\hline 15 & 16.60 & 23.29 & 28.30 & 16.00 & 23.94 & 29.11 \\
\hline 16 & 17.00 & 23.30 & 28.88 & 16.40 & 24.37 & 29.43 \\
\hline 17 & 17.30 & 24.46 & 29.41 & 16.60 & 24.70 & 29.69 \\
\hline 18 & 17.50 & 25.00 & 30.00 & 16.70 & 25.00 & 30.00 \\
\hline
\end{tabular}

\section{RESULTS}

The variation analysis of anthropometric indicators in the beginning (Table 2) and the end of the experiment (Table 3) shows that the dissipation of indicators does not show significant differences between the two studies, except the Body mass index, which shows a more pronounced dissipation of the indicator in the first study as compared to the last. Great variability is observed in the weight indicator both in the beginning and the end of the experiment, which to us is due on one hand to heterogeneity during the process of growth for pupils of each sex, but also to the alarming fact that among the pupils in the study there are such with overweight and obesity. This can also be confirmed by the maximum values of the Body mass index, namely 24.8 at the beginning of the experiment and 27.1 in the end. These values fall into the obesity column for the respective age and sex (Table 1).

Table 2. Variation analysis of results from the study of anthropometric indicators (september 2018)

\begin{tabular}{|c|c|c|c|c|c|c|c|}
\hline \multicolumn{2}{|c|}{ Study } & \multirow{2}{*}{ min } & $\max$ & $\mathbf{R}$ & $\operatorname{mean}$ & $\mathbf{S}$ & \multirow{2}{*}{ V\% } \\
\cline { 1 - 4 } № & Sample & & & & & & \\
\hline 1 & Height & 1.4 & 1.64 & 0.24 & 1.52 & 0.06 & 0.03 \\
\hline 2 & Weight & 31.8 & 61.1 & 29.3 & 42.5 & 8.1 & 66.07 \\
\hline 3 & Body mass index & 13.8 & 24.8 & 11 & 18.2 & 3.08 & 9.49 \\
\hline
\end{tabular}

Table 3. Variation analysis of results from the study of anthropometric indicators (may 2019)

\begin{tabular}{|c|c|c|c|c|c|c|c|}
\hline \multicolumn{2}{|r|}{ Study } & \multirow{2}{*}{$\min$} & \multirow{2}{*}{$\max$} & \multirow{2}{*}{$\mathbf{R}$} & \multirow{2}{*}{ mean } & \multirow{2}{*}{$\mathbf{S}$} & \multirow{2}{*}{$\mathrm{V} \%$} \\
\hline № & Sample & & & & & & \\
\hline 1 & Height & 1.45 & 1.67 & 0.22 & 1.55 & 0.06 & 0.03 \\
\hline 2 & Weight & 33 & 64 & 31 & 44.8 & 8.26 & 68.3 \\
\hline 3 & Body mass index & 13.72 & 27.1 & 13.38 & 18.6 & 3.2 & 10.3 \\
\hline
\end{tabular}

The obtained mean values of the indicator height in the beginning and the end of the experiment are mean $1=1.52 \mathrm{~m}$ and mean $2=$ $1.55 \mathrm{~m}$ respectively (Figure 1). The registered difference between these two mean values is $\mathrm{d}=0.03 \mathrm{~m}$. For the duration of the experiment September - May it is normal for pupils to grow taller, especially keeping in mind that marked growth of the musculoskeletal system is typical for eleven and twelve-year-olds. The obtained mean values of the indicator weight are mean $1=42.5 \mathrm{~kg}$ and mean $2=44.8 \mathrm{~kg}$ respectively, the difference being $\mathrm{d}=2.3 \mathrm{~kg}$, which shows that pupils increased in body 
weight over the course of the experiment. The mean values of the established Body mass index in the beginning and the end of the experiment are mean $1=18.2$ and mean $2=18.6$ respectively, the difference being insignificantly small $\mathrm{d}=0.4$,
BELOMAZHEVA-DIMITROVA S. which is statistically insignificant. The mean values of the Body Mass index in the beginning and the end of the experiment show that pupils generally have normal body weight.

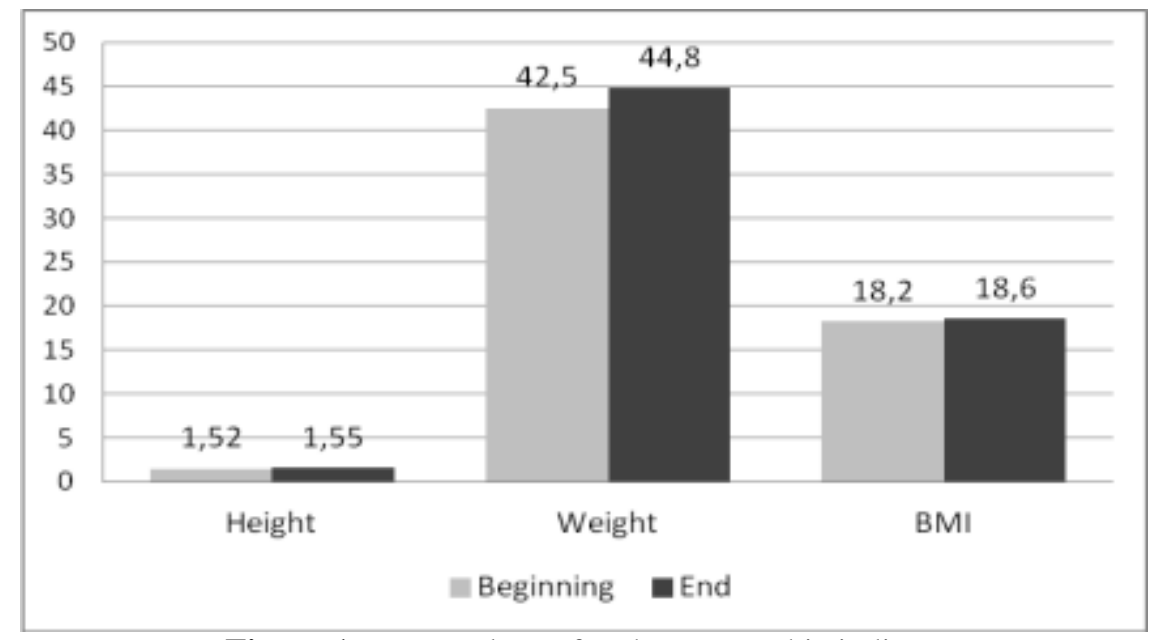

Figure 1. Mean values of anthropomorphic indicators

The results obtained from the study of anthropometric indicators show that the changes that have occurred in the children's bodies are due to normal physiological process of growth and development of the musculoskeletal system.

Table 4. Variation analysis of results from specialized tests (september 2018)

\begin{tabular}{|c|c|c|c|c|c|c|c|}
\hline & Study & $\min$ & $\max$ & $\mathbf{R}$ & mean & S & V\% \\
\hline № & Sample & & & & & & \\
\hline 1. & Depth of bend & -3 & 7 & 10 & -1.04 & 92.88 & 8.34 \\
\hline 2. & Depth of bend to the left & 32 & 45 & 13 & 37.6 & 3.81 & 14.55 \\
\hline 3. & Depth of bend to the right & 32 & 45 & 13 & 37.8 & 3.77 & 14.26 \\
\hline 4. & $\begin{array}{l}\text { Static strength endurance of } \\
\text { the abdominal muscles }\end{array}$ & 14 & 38 & 24 & 28.3 & 6.1 & 37.3 \\
\hline 5. & $\begin{array}{l}\text { Static strength endurance of } \\
\text { the back muscles }\end{array}$ & 16 & 36 & 20 & 26.2 & 5.34 & 28.9 \\
\hline 6. & $\begin{array}{l}\text { Dynamic strength endurance } \\
\text { of the abdominal muscles }\end{array}$ & 16 & 28 & 12 & 20.04 & 3.58 & 12.84 \\
\hline 7. & $\begin{array}{l}\text { Dynamic strength endurance } \\
\text { of the back muscles }\end{array}$ & 14 & 28 & 14 & 20.14 & 3.7 & 13.72 \\
\hline
\end{tabular}

Table 5. Variation analysis of results from specialized tests (may 2019)

\begin{tabular}{|c|c|c|c|c|c|c|c|}
\hline \multicolumn{2}{|c|}{ S. } & min & max & R & mean & S & V\% \\
\hline 1. & Depth of bend & -4 & 5 & 9 & -0.33 & 2.6 & 6.7 \\
\hline 2. & Depth of bend to the left & 32 & 45 & 13 & 36.6 & 3.9 & 15.2 \\
\hline 3. & Depth of bend to the right & 31 & 45 & 14 & 39.9 & 3.9 & 15.5 \\
\hline 4. & $\begin{array}{c}\text { Static strength endurance of } \\
\text { the abdominal muscles }\end{array}$ & 24 & 50 & 26 & 43.04 & 6.6 & 44.1 \\
\hline 5. & $\begin{array}{c}\text { Static strength endurance of } \\
\text { the back muscles }\end{array}$ & 26 & 48 & 22 & 40.9 & 6.4 & 41.5 \\
\hline 6. & $\begin{array}{c}\text { Dynamic strength endurance } \\
\text { of the abdominal muscles }\end{array}$ & 28 & 39 & 11 & 31.5 & 3.05 & 9.36 \\
\hline 7. & $\begin{array}{c}\text { Dynamic strength endurance } \\
\text { of the back muscles }\end{array}$ & 24 & 36 & 12 & 30.2 & 3.66 & 13.46 \\
\hline
\end{tabular}


Tables 4 and 5 show the variation analysis of results from specialized tests in the beginning (Table 4) and the end of the experiment (Table 5). A greater diversity of the studied indicators is observed in the initial phase, while in the end of the experiment the dissipation of the indicators decreases. An exception is the test results for static strength
BELOMAZHEVA-DIMITROVA S. endurance of the abdominal and back muscles, where the indicators for dissipation maintain high values in the second study too. This is probably due to the poor physical fitness of children in the beginning of the experiment, the level of difficulty of the test and the different output level.

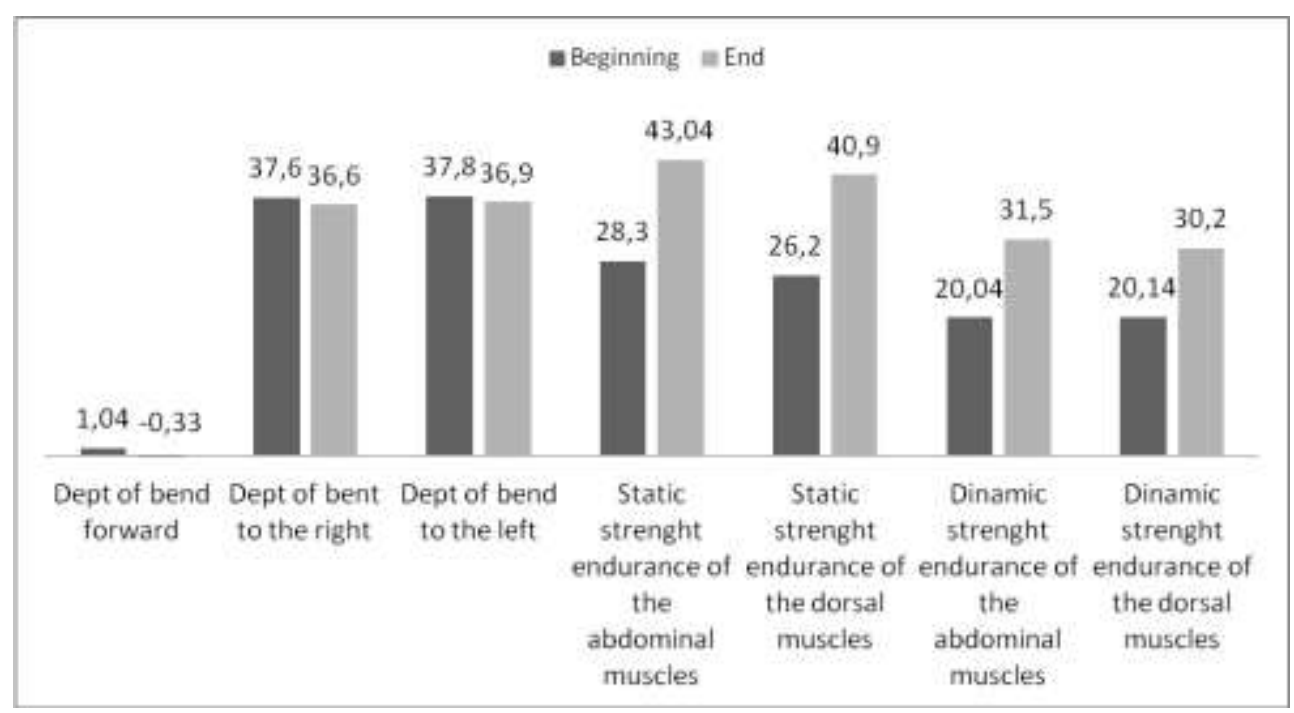

Figure 2. Mean values of indicators from specialized tests

The obtained mean values of the indicator depth of bend in the beginning and the end of the experiment are mean $1=-1.04 \mathrm{~cm}$ and mean $2=-0.33 \mathrm{~cm}$ respectively (Figure 2). The registered difference between these two mean values is $\mathrm{d}=1.37 \mathrm{~cm}$, which is statistically insignificant when the Student's t criterion for dependent samples is 0.11 and guarantee probability under $95 \%$, degree of freedom $\mathrm{k}=15$ and $\alpha-0.05$ (Table 6). This means that the applied set of corrective exercises does not contribute to making the spine more flexible. This is understandable, keeping in mind that the exercises mainly aim at strengthening the body corpus muscles and less at making the spine more flexible, which does not contradict the principles of corrective gymnastics.

The obtained mean values of the tests for depth of bend to the right and left in the beginning and the end of the experiment are mean $1=37.6$ $\mathrm{cm}$ and mean $2=36.6 \mathrm{~cm}$ and mean $1=37.8 \mathrm{~cm}$ and mean $2=39.9 \mathrm{~cm}$ respectively, the differences being $\mathrm{d}=1$ and $\mathrm{d}=2.1$ respectively, which differences are statistically insignificant and the guarantee probability is under $95 \%$ (Table 6). This shows that the applied methodology does not lead to improving the flexibility of pupils' spine to the sides.

The obtained mean values of the tests for static strength endurance of back and abdominal muscles in the beginning and the end of the experiment are mean $1=28.3 \mathrm{~s}$ and mean2 $=43.04 \mathrm{~s}$ and mean $1=26.2 \mathrm{~s}$ and mean $2=40.9 \mathrm{~s}$ respectively, the differences being $\mathrm{d}=14.74 \mathrm{~s}$ and $\mathrm{d}=14.7 \mathrm{~s}$ respectively, which are statistically significant when the Student's $t$ criterion is 7.38 and 7.62 respectively and guarantee probability $\mathrm{Pt}>99 \%$ (Table 6). This means that the applied set of corrective exercises in Physical education class leads to improvement in static strength endurance of abdominal and back muscles, which is particularly important for keeping the spine upright and for counteracting both poor posture and spinal deformities.

The obtained mean values of the tests for dynamic strength endurance of back and abdominal muscles in the beginning and the end of the experiment are mean $1=20.04 \mathrm{~s}$ and mean $2=31.5 \mathrm{~s}$ and mean $1=20.14 \mathrm{~s}$ and mean $2=30.2 \mathrm{~s}$ respectively, the differences being $\mathrm{d}=11.46 \mathrm{~s}$ and $\mathrm{d}=10.06 \mathrm{~s}$ respectively, which are statistically significant when the 
Student's $\mathrm{t}$ criterion is 8.44 and 6.14 respectively and guarantee probability $\mathrm{Pt}>99 \%$. This confirms the research hypothesis
BELOMAZHEVA-DIMITROVA S. that the applied set of exercises in Physical education class will lead to positive changes in the muscles supporting the spine.

Table 6. Comparative analysis of the results of the specialized tests

\begin{tabular}{|c|c|c|c|c|c|c|c|c|}
\hline \multicolumn{2}{|c|}{ Study } & \multirow{2}{*}{ mean1 } & \multirow{2}{*}{ S1 } & \multirow{2}{*}{ mean2 } & \multirow{2}{*}{$\mathbf{S 2}$} & \multirow{2}{*}{ d } & \multirow{2}{*}{$\mathbf{t}$} & \multirow{2}{*}{$\mathbf{P t}$} \\
\hline № & Name & & & & & & & \\
\hline 1. & Depth of bend & 1.04 & 2.88 & -0.33 & 2.6 & 1.37 & 0.11 & $<95 \%$ \\
\hline 2. & Depth of bend to the left & 37.6 & 3.81 & 36.6 & 3.9 & 1 & 0.42 & $<95 \%$ \\
\hline 3. & Depth of bend to the right & 37.8 & 3.77 & 39.9 & 3.9 & 2.1 & 0.47 & $<95 \%$ \\
\hline 4. & $\begin{array}{l}\text { Static strength endurance of } \\
\text { the abdominal muscles }\end{array}$ & 28.3 & 6.1 & 43.04 & 6.6 & 14.74 & 7.38 & $>99 \%$ \\
\hline 5. & $\begin{array}{l}\text { Static strength endurance of } \\
\text { the back muscles }\end{array}$ & 26.2 & 5.34 & 40.9 & 6.4 & 14.7 & 7.62 & $>99 \%$ \\
\hline 6. & $\begin{array}{l}\text { Dynamic strength endurance } \\
\text { of the abdominal muscles }\end{array}$ & 20.04 & 3.58 & 31.5 & 3.05 & 11.46 & 8.44 & $>99 \%$ \\
\hline 7. & $\begin{array}{c}\text { Dynamic strength endurance } \\
\text { of the back muscles }\end{array}$ & 20.14 & 3.7 & 30.2 & 3.66 & 10.06 & 6.14 & $>99 \%$ \\
\hline
\end{tabular}

\section{CONCLUSIONS}

Some of the pupils are overweight or obese, but the mean BMI values in the studied sample are within the norm for the age group.

The results obtained by specialized tests indicate good efficiency of the applied set of exercises in regard to strengthening the body muscles and achieving a statistically significant increase in dynamic and static muscle strength of abdominal and back muscles, which is a precondition for improving and maintaining body posture in pupils' everyday life.

The results obtained confirm the research hypothesis.

Increasing motor skills and strengthening body muscles lead to improvement of quality while performing different physical activities, therefore increase in student satisfaction, which is one of the elements of "quality of life".

\section{REFERENCES}

1. Simeonov, D., Geography of public health in Bulgaria. Social aspects. "STIKERI-BE", Varna, 2013.

2. Simeonov, D., Socio-geographic assessment of quality of life in the region of Veliko Tarnovo. Proceedings of Scientific conference in honor of the 70th anniversary of Assoc. Prof. Dr. Vladimir Popov, Veliko Tarnovo, pp. 562-572, 2010.
3. Reiman, M., Manske, R., Functional testing in human performance, Human Kinetics Europe Ltd; 1st edition, 2009.

4. Cook, G., Burton, L., Hoogenboom, B., Pre-participation screening: The use of fundamental movements as an assessment of function - Part 1. North American Journal of Sports Physical Therapy, Vol. 1, Suppl. 2, pp. $62-72,2006$.

5. Cook, G., Burton, L., Hoogenboom, B., Pre-participation screening: The use of fundamental movements as an assessment of function - Part 2. North American Journal of Sports Physical Therapy, Vol. 1, Suppl. 3, pp. 132- 139, 2006.

6. Okada, T., Huxel, K. C., Nesser, T. W., Relationship Between Core Stability, Functional Movement, and Performance. Journal of Strength and Conditioning Research, Volume 25 - Issue 1 - p 252-261, 2010.

7. Duncan, M., Stanley, M., Wright, S., The association between functional movement and owerweight and obesity in British primary school children. BMC Sport Science, Medicine, and Rehabilitation, Vol. 5, Suppl.11, pp.1-8, 2013.

8. Richardson, C., Jull, G., Hodges, P. and Hides, J., Therapeutic exercise for Spinal Segmental Stabilization in Low Back Pain. Scientific Basis and Clinical Approach. Edinburgh, NY: Churchill Livingstone, 1999.

9. Akuthota, V., Ferreiro, A., Moore, T., Fredericson, M., Core Stability Exercise 
Principles. Current Sports Medicine Reports, Volume 7 - Issue 1 - pp. 39-44, 2008.

10.Fredericson, M., Moore, T., Muscular Balance, Core Stability, and Injury Prevention for Middle- and Long-Distance Runners. Physical Medicine and Rehabillitation Clinic Nord America, Vol. 16, pp. 669-689, 2005.

11.Hodges PW, Richardson, CA., Inefficient muscular stabilization of the lumbar spine associated with low back pain. A motor control evaluation of transversus abdominis. Spine, Vol. 21, pp. 2640-2650, 1996.

12.Angelova, P., Petkov, P., Comparative analisis of the functional status of the spine in students men and women. Trakia Journal of Sciences, Vol. 13, Suppl. 1, pp 403-406, 2015.
BELOMAZHEVA-DIMITROVA S.

13.Angelova, P., Physical development analysis according to anthropometric indicators of male students in the Trakia university. Trakia Journal of Sciences, Vol. 17, Suppl. 1, pp 638-642, 2019.

14.Pandulchev, D., Theofylaktos, A., DilovaNeykova, Ts., Stefanov, S. (2017). Using the functional movement screen to evaluate physical education students. Pedagogical Almanac, Issue 2, pp. 199-204, 2017.

15.BMI and BMI-for-Age Look-Up Tables for Children and Adolescents 5-18 Years of Age and BMI Look-Up Tables for NonPregnant, Non-Lactating Adults $\geq 19$ Years of Age. Food and nutrition technical assistant. USAID, 2013.

16.Karaneshev, G., Milcheva, D., Yancheva, S., Methods for diagnosis and measurement in physiotherapy, National Sports Academy Sofia, 1991. 